\title{
QUANTITATIVE VIBRATIONAL METHODS DEVELOPMENT AND ITS PERFORMANCE COMPARISON TO COLORIMETRY ON THE ASSAY OF KANAMYCIN SULFATE
}

\author{
ILMA NUGRAHANI ${ }^{1 *}$, RIZKA FAUZIA ${ }^{2}$
}

${ }^{1}$ School of Pharmacy, Bandung Institute of Technology, Bandung, Indonesia, ${ }^{2}$ Pyridam Farma Pharmaceutical Company, Cianjur, Indonesia Email: ilma_nugrahani@fa.itb.ac.id

Received: 10 Mar 2019, Revised and Accepted: 03 Jun 2019

\begin{abstract}
Objective: The purpose of this study was to develop and validate Fourier Transform Infra-Red (FTIR) method for a non-chromophore antibiotic, kanamycin sulfate. Afterward, it was compared to other quantitative methods, namely colorimetry using ninhydrin.

Methods: FTIR was used to determine the level of kanamycin sulfate. Firstly, the absorbance spectra were measured. To increase the specificity, it used mathematical derivation, which would separate the active compound's spectrum clearer from the other component of the dosage form. The clearest absorbance spectra was found at $1540-1480 \mathrm{~cm}^{-1}$, as the N-H bending, which then was used as the base for the quantitative analysis. This method was then applied to determine the kanamycin sulfate content in the commercial reconstitution-injection dosage form. Afterward, the analysis performance compared to another method which had established, namely colorimetry. The counterpart method was using ninhydrin as the chemical reagent to produce a chromophore, which able to be measured by visible spectrophotometry. Validation test checked the parameters such as linearity, LOD, LOQ, range, accuracy, and precision, continuing to evaluate and to compare the time and material involved with the colorimetry as the counterpart.
\end{abstract}

Results: The results showed that FTIR for kanamycin sulfate lavel determination gave linearity within the range $0.12-1.5 \% \mathrm{w} / \mathrm{w}$, with the $\mathrm{r}=$ 0.99975. Meanwhile, the LOD and LOQ were $0.04 \%$ and $0.12 \% \mathrm{w} / \mathrm{w}$. There were no significant differences between the results of content determination of the antibiotic from the two methods. However, FTIR shows more advantages on time reducing, more straightforward preparation, solvents reducing, less costly, and more convenient.

Conclusion: FTIR is suitable to be an alternative method for quantifying kanamycin sulfate in a dosage form accurately, sensitive, and economist. This method is superior in its accuracy, precision, and simplicity compared to the colorimetry method using UV spectrometer as the counterpart.

Keywords: Kanamycin sulfate, Quantitative FTIR, Vibrational spectrophotometry, Derivative, Visible spectrophotometry, Ninhydrin-colorimetry

(C) 2019 The Authors. Published by Innovare Academic Sciences Pvt Ltd. This is an open access article under the CC BY license (http://creativecommons.org/licenses/by/4.0/J DOI: http://dx.doi.org/10.22159/ijap.2019v11i4.32991

\section{INTRODUCTION}

Kanamycin sulfate is an aminoglycoside class antibiotic obtained from Streptomyces kanamyceticus culture, working as a broad spectrum bactericidal agent. Kanamycin works to inhibit protein synthesis by binding irreversibly to the $30 \mathrm{~S}$ ribosome subunit [1]. This antibiotic, in its sulfate form, is used to treat various infections, especially tuberculosis [2-4]. Its preparations on the market are available in capsule and injection form $[1,5]$. The raw substance is a white crystal powder that is odorless, hygroscopic, ease soluble in water, insoluble in acetone, ethyl acetate, and benzene [6-9].

Quantitative determination of kanamycin sulfate in compendia was performed using the antibiotic potential test method and highperformance liquid chromatography (HPLC) method [6, 9]. Besides, It also mentioned the ninhydrin reaction for the qualitative purpose, in the substance identification procedure [8]. In practice, microbiological test methods have limitations, including quite a lot of work steps and the longer time. Meanwhile, HPLC method has a high sensitivity but requires a complicated maintenance, and need the expensive column and mobile phase [10].

On the other hand, generally, the FTIR method is for identification and determination of functional groups qualitatively [11-13]. Quantitative determination of levels using this method is still rare and not widely done. Whereas, the vibration method has several advantages, including more straightforward sample preparation, minimal solvent use, comfortable, rapid, and non-destructive. Besides, it consumes relatively more economist in costs and environmentally friendlier.

So far, another non-chromatographic spectrophotometry technique for kanamycin sulfate is an un-direct visible-light spectrophotometry or colorimetry, which has been reported before $[14,15]$. However, as known, the pre-treatment by chemical reaction requires some checks to ensure the stability and entirely of the product. The purpose of this study was to develop and validate FTIR method as a new-rapid way to determine the content of kanamycin sulfate in its solid form, directly. The method then was compared to the colorimetry supported by UV spectrometer.

Kanamycin sulfate determination used the infra-red absorption of the specific chemical bonds in its molecule $[11,16]$. This compound was expected to produce a typical spectrum formed by absorption of infrared wave numbers by the amine $(\mathrm{N}-\mathrm{H})$ and ether $(\mathrm{C}-\mathrm{O})$ groups, as shown in fig. 1.

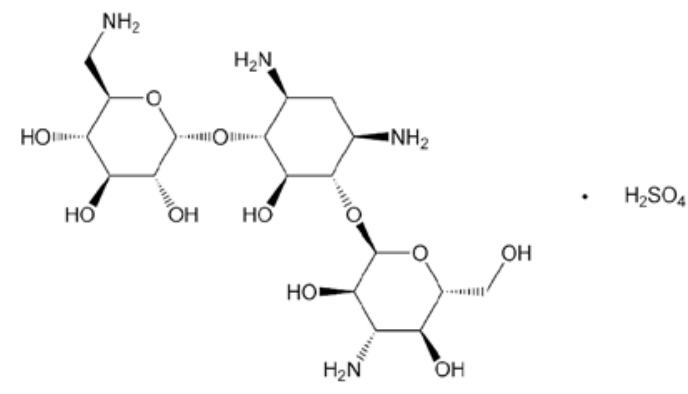

Fig. 1: Kanamycin sulfate chemical structure [8]. No chromophore can be found

As known, FTIR spectrophotometer is the development of an IR spectrophotometer, which is one tool that can be used to analyze a compound based on the infrared spectrum produced [17-21].

Visible spectrophotometry is a measurement method based upon the measurement of absorbance (A) or transmittance (T) of an analyte solution in a transparent cell with a thickness of $b$ 
centimeters at the wavelength. Generally, the concentration of analytes will be proportional to absorbance $[22,23]$. It is indicated by the Lambert-Beer equation as follows:

$$
\mathrm{A}=-\log \mathrm{T}=\Sigma \mathrm{bc}
$$

The highlighted innovation in this manuscript is the specific spectrum of kanamycin sulfate for assay using FTIR, supported by mathematical derivation to increase its selectivity. Moreover, it proofs that the method is valid and more efficient compared to the solution spectrophotometry. Finally, this report expected to enrich the analytical methods for pharmaceutical and the dosage form, which will be useful in some conditions with the limit resources. By the rapid and straightforward steps, the vibrational spectroscopy, which is still rarely used in quantitative measurement, should be considered as an adequate alternative method.

\section{MATERIALS AND METHODS}

\section{Materials}

Kanamycin sulfate (Drug and Food Monitoring Institution, Indonesia) comparison, $\mathrm{KBr}$ crystal spectra grade (Merck, Germany), acetone (PT. Smart Lab Indonesia), ninhydrin (Merck, Germany), aquadest, and kanamycin sulfate reconstitution for the injection dosage form.

\section{Apparatus}

We used: milligram electronic scales, pestles, mortars, FTIR plates, pellet presses, ovens, volumetric flasks, micro-pipettes, electric heaters, FTIR (Jasco-4200 type A), and Hewlett Packard 8453 Spectrophotometer Diode Arrays.

\section{Methods}

The research was conducted by developing the FTIR method on the determination of kanamycin sulfate levels. The validation of the FTIR method was carried out by measuring the raw mixture of kanamycin sulfate and potassium bromide in several series of concentrations $(\% \mathrm{w} / \mathrm{w})$ using FTIR. The spectrum obtained was next converted into absorbance and derivatized. The spectrums that produced the best linearity and specificity were chosen to determine the AUC value, then the linearity, accuracy, precision, range, detection limit, and quantification limits were determined. The method was next used to determine the levels in its injection preparation samples.

Determination of antibiotic levels of kanamycin sulfate using colorimetry was carried out by doing pretreatment by reacting of kanamycin sulfate using ninhydrin. This method recently has been established by Das et al., which generated from the qualitative method stated by compendium [14]. The purple yielded, can absorb the wavelength range of visible light $564 \mathrm{~nm}[14,15]$. Next, the maximum wavelength was selected and tested by the verification method. The verification parameters tested included linearity, accuracy, precision, range, detection limit, and quantification limits. The verified method is then used to determine the levels of kanamycin sulfate in the injection preparation sample. Both methods are compared based on sensitivity parameters, test time, cost estimation, and simplicity of the method. The results of the assay with the two methods were compared the unpaired t-test data statistically with a $95 \%$ confidence level.

\section{Development of the FTIR method}

\section{Measurement of raw FTIR spectrum of kanamycin sulfate}

A mixture of kanamycin sulfate in $\mathrm{KBr}$ crystals with a concentration of $0.25-1.5 \% \mathrm{w} / \mathrm{w}$ were prepared. Each mixture was weighed as much as $10 \mathrm{mg}$ then compressed with a pellet press. Plates were measured at $4000-400 \mathrm{~cm}^{-1}$ wave number using FTIR, and each was done three times.

\section{Derivatization of raw FTIR spectrum of kanamycin sulfate}

The FTIR spectrum obtained was corrected by baseline and derivated using the program which is available on the Jasco-4200 FTIR type A (Japan). The second area under the curve (AUC) was calculated with axis $=0$ in several ranges of wave numbers.

\section{Determination of the range of raw FTIR wave numbers of kanamycin sulfate}

Selection of the wave number range to determine the AUC was carried out at wave numbers $1720-1610 \mathrm{~cm}^{-1}$ ( $\mathrm{C}=0$ stretching), $1540-1480 \mathrm{~cm}^{-1}$ (N-H bending) and 1190-1120 $\mathrm{cm}^{-1}$ (alcohol) [15, 19]. Furthermore, a graph of the relationship between the standard concentrations of kanamycin sulfate in $\mathrm{KBr}$ crystals to the AUC in the two wave number ranges was selected and a wave number range that shows the best linearity is chosen.

\section{Validation of the FTIR method}

Validation test included parameters of specificity, linearity, determination of the range, limit of detection and quantitation, accuracy and precision inter-and intraday. All were done to the standard of kanamycin sulfate and its mixture with the matrices.

Determination of the reconstituted injection sample content of kanamycin sulfate using FTIR

Determination of the concentration of kanamycin sulfate injection was carried out by weighing each of 6 kanamycin sulfate vials of a brand powder-reconstitution for injection preparation, next calculating the average. All reconstituted for injection were grounded homogeneously. Afterward, it was sampled with $1.0 \%$ kanamycin sulfate concentration and mixed into $\mathrm{KBr}$ crystals up to $100 \mathrm{mg}$. From the mixture weighed 10 mg then measured and determined using FTIR.

Determination of kanamycin sulfate injection sample by visible spectrophotometry method $[14,15]$

\section{Preparation of ninhydrin reagent solutions}

The ninhydrin solution was made by dissolving $0.2 \mathrm{~g}$ ninhydrin in 94 $\mathrm{ml}$ of distilled water and $6 \mathrm{ml}$ of acetone until a clear solution was formed. The solution was stored in a tightly closed container and protected from heat or light [13].

\section{Preparation of standard stocks of kanamycin sulfate}

The stock solution was made by dissolving $250 \mathrm{mg}$ kanamycin sulfate standard in $2 \mathrm{ml}$ of distilled water and $20 \mathrm{ml}$ of ninhydrin. The solution was then heated for $5 \mathrm{~min}$ at $80-100^{\circ} \mathrm{C}$ to form purple. After cooling, the solution was put into a $25 \mathrm{ml}$ volumetric flask and next filled with distilled water to the limit mark $(10 \mathrm{mg} / \mathrm{ml})$.

\section{Determination of the maximum wavelength of compound results}

$2.5 \mathrm{ml}$ of standard solution in a $10 \mathrm{ml}$ volumetric flask added distilled water to the boundary mark $(2.5 \mathrm{mg} / \mathrm{ml})$. The solution was then measured using a UV-Vis spectrophotometer in a wavelength range of $200-800 \mathrm{~nm}$ and determined wavelengths, which gave maximum absorbance.

\section{Analysis method verification}

Method verification is done by testing linearity, accuracy, precision, range, detection limit, and quantification parameters. In linearity testing, six test solutions were made with concentration variations of $2 ; 2.25 ; 2.5 ; 2.75 ; 3$; and $3.25 \mathrm{mg} / \mathrm{ml}$ was then measured using a UV-Vis spectrophotometer at the maximum wavelength. Each was made three times. After that, the relationship between absorbance and the standard concentration of kanamycin sulfate was graphed, and its linearity was determined.

\section{Determination of injection samples of kanamycin sulfate levels using colorimetry}

Determination of the concentration of kanamycin sulfate injection was carried out by weighing each 6 of kanamycin sulfate vial and after that calculating the average. All injection samples were ground homogeneously and later was made a test solution equivalent to 2.5 $\mathrm{mg} / \mathrm{ml}$. The test solution was measured and determined using UVVis spectrophotometer.

\section{Comparative study of FTIR methods and colorimetry}

The validated FTIR method then was compared to the fixed colorimetry. The parameters evaluated were: test time, cost 
estimation, and simplicity based on the steps involved. The results of the assay with the two methods were compared statistically using the unpaired t-test. The value of $t$ count is determined and compared to the value of $t$ two-way table with a degree of confidence or $95 \%$ confidence interval $(\mathrm{CI})$.

\section{RESULTS AND DISCUSSION}

Compounds that can absorb energy are that have a chromophore group, which is a group within a molecule plays a role in absorbing the molecule at a specific wavelength. The moieties are the conjugated double bonds, carbonyl groups or inorganic groups. Compounds that do not have it still can be measured using the spectrophotometric method using a reaction, namely chemical derivation. In this method, the compounds analyzed will absorb energy in the form of rays from the radiation source at the wavelength of the visible light $(400-800 \mathrm{~nm})$. On the other hand, for FTIR, the derivation also is performed as a mathematical manipulation terminology. The most advantages of this vibrational method are its simplicity, green and cost-efficient, due to no solvent needed for the solid direct analysis.

Development of FTIR to determine the level of kanamycin sulfate was carried out by selecting the spectrum, derivation, and determining wavenumbers. Firstly, it measured the mixture of kanamycin sulfate in $\mathrm{KBr}$ crystals with a concentration range of $0.25-1.5 \% \mathrm{w} / \mathrm{w}$. The results revealed in fig. 2 :

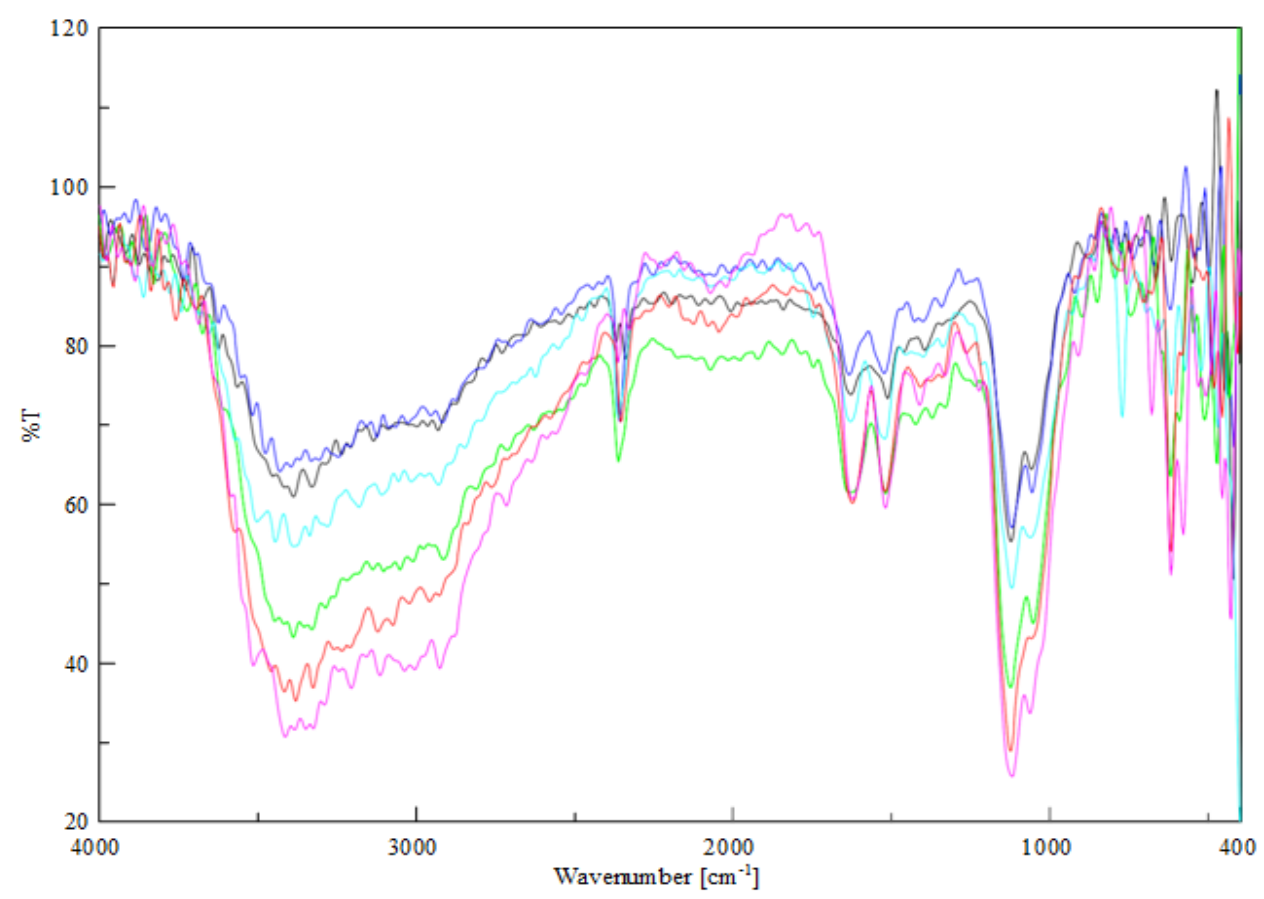

Fig. 2: Spectrums of \%T of kanamycin sulfate at 4000-400 $\mathrm{cm}^{-1}$ from the concentrations of $0.25 \%$ w/w (black line)-1.50\% w/w (purple line)

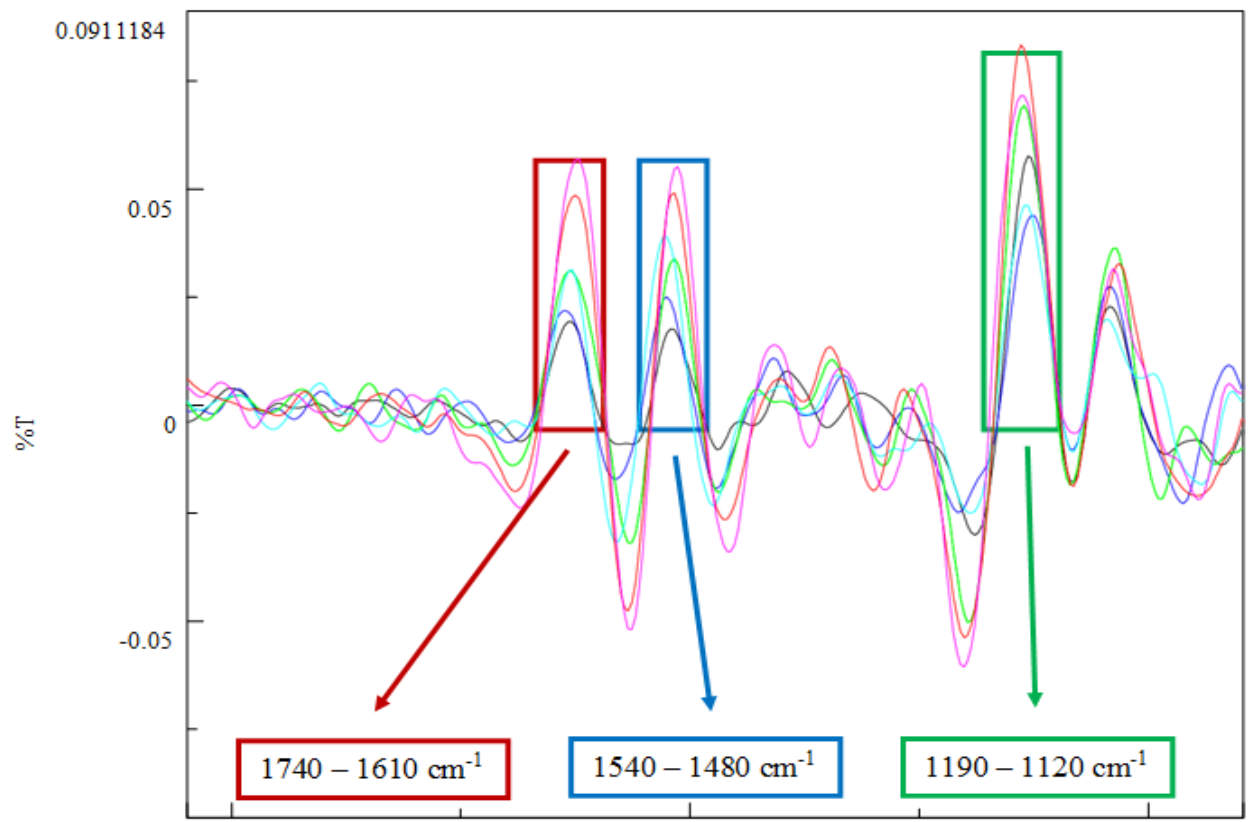

Fig. 3: Spectrums of the first derivate of kanamycin sulfate at $2000-1000 \mathrm{~cm}^{-1}$ in the percentages (w/w): 0.25 (black line), 0.50 (dark blue), 0.75 (green), 1.00 (sea blue), 1.25 (red), and 1.5 (purple) 
After obtaining the spectrums, then derived it by first correcting the baseline spectrum and using the program which has consisted in FTIR Jasco-4200 type A. From the spectrum derivatives, the area under the curve (AUC) was determined. Then, the clearest peak and un-influenced by others was selected as shown in fig. 3 .

The selected peaks were from the wave number ranges of 1720-1610 $\mathrm{cm}^{-1}, 1540-1480 \mathrm{~cm}^{-1}$, and $1190-1120 \mathrm{~cm}^{-1}$. Those spectra represent the carbonyl stretching, amine bending, and alcohol, respectively [15,
19], which can be confirmed in the structure in fig. 1. Next, they were converted to absorbance value. A mathematical derivation was then conducted to increase its selectivity. Furthermore, the AUC of each concentration was measured and next determined by linearity. The results revealed that the most linear peak, as shown in table 1 , was at $1540-1480 \mathrm{~cm}^{-1}$. This spectrum represented the absorption by the $\mathrm{N}-\mathrm{H}$ bond of the primary amine from the antibiotic. Further, it was the selected spectrum for determining the levels of kanamycin sulfate in injection preparations.

Table 1: Concentration of kanamycin sulfate and average AUC of derivate absorbance

\begin{tabular}{llll}
\hline Concentration $(\% \mathbf{w} / \mathbf{w})$ & \multicolumn{3}{l}{ Average AUC from each range of wavelength $\left(\mathbf{c m}^{-1}\right) \pm \mathbf{S D}$} \\
\cline { 2 - 4 } & $\mathbf{1 7 2 0 - 1 6 1 0}$ & $\mathbf{1 5 4 0 - 1 4 8 0}$ & $\mathbf{1 1 9 0 - 1 1 2 0}$ \\
\hline 0.25 & $0.61314 \pm 0.03037$ & $0.57675 \pm 0.00172$ \\
0.5 & $0.82659 \pm 0.02152$ & $0.84675 \pm 0.01813$ & $0.88814 \pm 0.05247$ \\
0.75 & $1.06916 \pm 0.07976$ & $1.10811 \pm 0.06438$ & $1.47298 \pm 0.03209$ \\
1.0 & $1.29953 \pm 0.02920$ & $1.35776 \pm 0.03579$ & $1.95621 \pm 0.09889$ \\
1.25 & $1.57683 \pm 0.27431$ & $1.65887 \pm 0.08517$ & $2.40671 \pm 0.05861$ \\
1.5 & $1.84575 \pm 0.05110$ & $1.90323 \pm 0.07298$ & $3.42056 \pm 0.37723$ \\
Linearity $(\mathrm{r})$ & $0.99895 \pm 0.01050$ & $0.99975 \pm 0.00672$ & $0.99940 \pm 0.02169$ \\
\hline
\end{tabular}

Note: AUC: area under the curve; $n=3$.

The FTIR method afterward was validated against parameters, namely specificity, linearity, accuracy, precision, range, LOD and LOQ. Specificity test compared the spectrum derivative of kanamycin sulfate against injection sample. The results showed that there was no difference between the standard with kanamycin

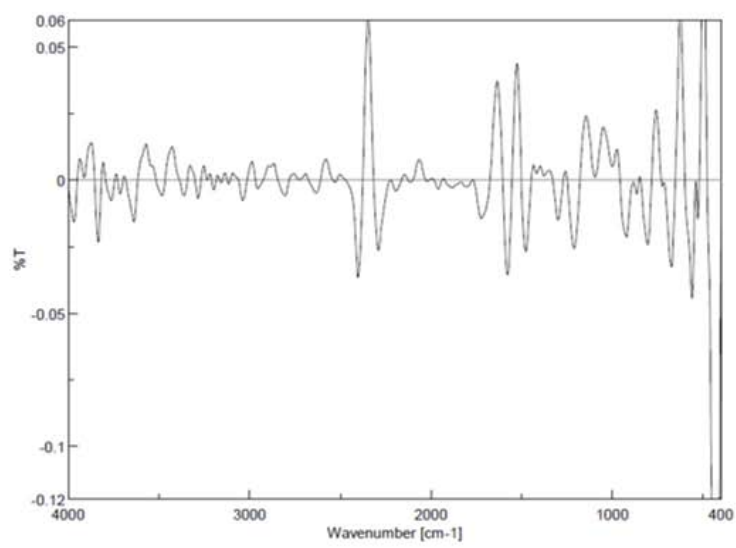

(a) sulfate injection samples as shown in fig. 4, especially in the selected area of quantification. It means that all matrices do not produce the$\mathrm{NH}$ primary stretching. Hence, it can state that the method of analysis of kanamycin sulfate using FTIR was not affected by the matrix contained in the sample.

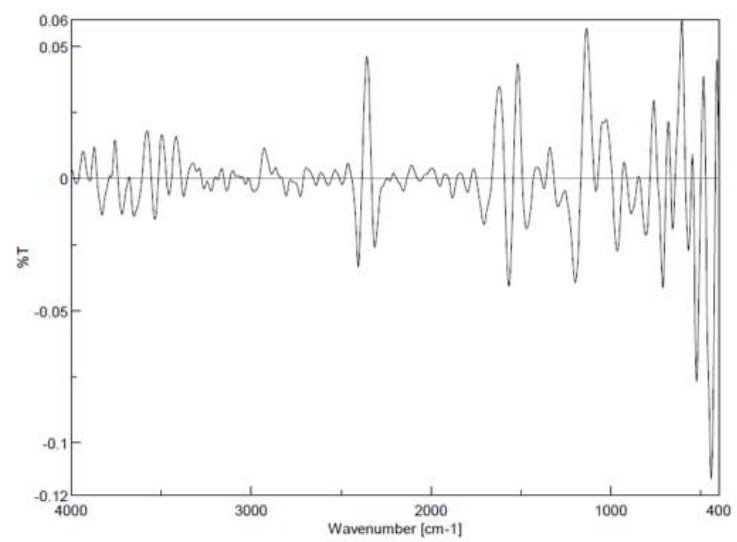

(b)

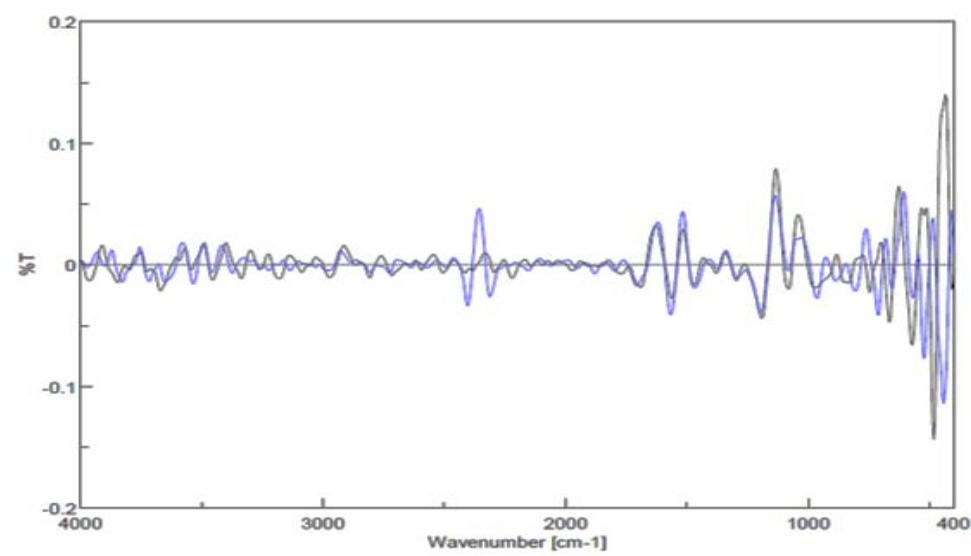

(c)

Fig. 4: Kanamycin sulfate $1 \% \mathrm{w} / \mathrm{w}$ (c) overlaid spectrum (a) and (b) 
Linearity was determined by plotting the relationship between the standard concentrations of kanamycin sulfate in $\mathrm{KBr}$ with the AUC spectrum derivative obtained from the measurement results. The six variations of concentration $(\% \mathrm{w} / \mathrm{w})$ were measured three times. Linearity was expressed in the correlation coefficient $(r)$ in the curve regression equation $\mathrm{y}=\mathrm{bx}+\mathrm{an}$ as shown in table 2 and fig. 5 .

Table 2: Calibration data of kanamycin sulfate using FTIR method

\begin{tabular}{|c|c|}
\hline The concentration of kanamycin sulfate $(\% \mathrm{w} / \mathrm{w})$ ] & Average of AUC derivated absorbance \pm SD \\
\hline 0.25 & $0.57675 \pm 0.00172$ \\
\hline 0.50 & $0.84675 \pm 0.01813$ \\
\hline 0.75 & $1.10811 \pm 0.06438$ \\
\hline 1.00 & $1.35776 \pm 0.03579$ \\
\hline 1.25 & $1.65887 \pm 0.08517$ \\
\hline 1.50 & $1.90323 \pm 0.07298$ \\
\hline
\end{tabular}

Note AUC: area under the curve; $\mathrm{n}=3$.

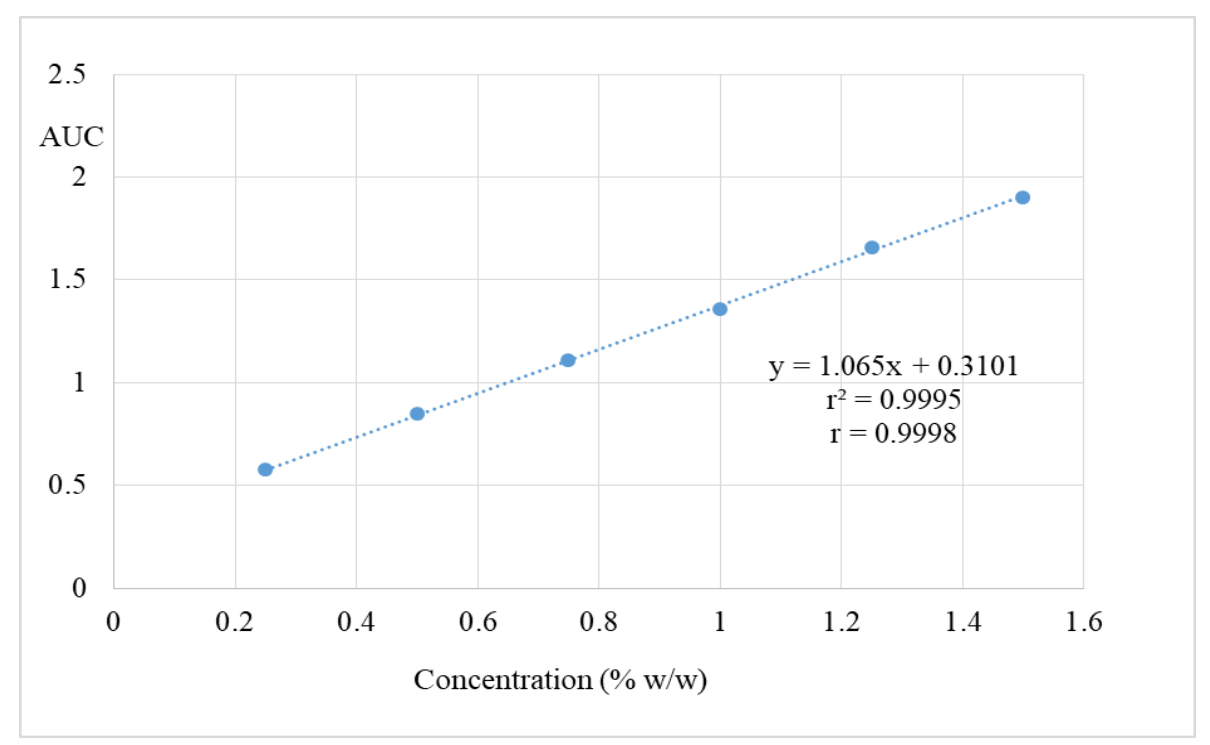

Fig. 5: Standard calibration curve of kanamycin sulfate standard, (note: AUC= area under the curve)

From the curve above obtained a linear regression equation $\mathrm{y}=$ $1.065 \mathrm{x}+0.3101$ in the concentration range over $0.25-1.5 \% \mathrm{w} / \mathrm{w}$ with the correlation coefficient $(\mathrm{r})=0.9998$ and $\mathrm{Vx} 0=0.014$. The value of $r \geq 0.999$ and $V x 0 \leq 2.0 \%$ indicated that the FTIR method fulfilled the acceptability requirements for linearity. The highest concentration is $1.5 \% \mathrm{w} / \mathrm{w}$ due to the technical problem if it more than this value. Too much compound will need much $\mathrm{KBr}$ and yields the opaque pellet, which is not good for measurement.

Accuracy test determined the standard of kanamycin sulfate at concentrations equivalent to $80 \%, 100 \%$, and $120 \% \mathrm{w} / \mathrm{w}$. Measurement of each concentration replicated three times. The percentage of recovery from the test results as shown in table 3 are 100.23\%; 99.18\%; and $100.27 \% \mathrm{w} / \mathrm{w}$. These three values fulfill the acceptability requirements' accuracy because they are in the range of $98-102 \% \mathrm{w} / \mathrm{w}$.

Precision is a measure that shows the degree of conformity between individual test results, calculated based on the average. Precision based on the standard deviation or relative standard deviation (coefficient of variation) value. It was determined by measuring the standard of kanamycin sulfate with an equivalent concentration of $100 \%$ and repeated six times in the day and carried out on three different days of analysis for intraday and inter-day precision.

Intraday precision was performed to determine precision on one test day or in a close time. The variance coefficient value obtained from each testing day as shown in table 4 was $1.14 \% ; 0.69 \%$; and $0.76 \%$. All values were $\leq 2 \%$ so that they met the precision acceptance requirements.

Table 3: Accuracy of kanamycin sulfate from the FTIR method

\begin{tabular}{|c|c|c|c|c|}
\hline Concentration $(w / w)$ & AUC & $\begin{array}{l}\text { Average of AUC } \\
\pm \text { SD }\end{array}$ & Theoretical AUC? & Recovery (\%) \\
\hline $80 \%$ & $\begin{array}{l}1.17716 \\
1.15357 \\
1.16371\end{array}$ & $1.16481 \pm 0.01183$ & 1.1621 & $100.23 \%$ \\
\hline $100 \%$ & $\begin{array}{l}1.36783 \\
1.36009 \\
1.36353\end{array}$ & $1.36382 \pm 0.00388$ & 1.3751 & $99.18 \%$ \\
\hline $120 \%$ & $\begin{array}{l}1.58209 \\
1.62127 \\
1.57402\end{array}$ & $1.59246 \pm 0.02527$ & 1.5881 & $100.27 \%$ \\
\hline
\end{tabular}

AUC: area under the curve. Note: $\mathrm{n}=3$ 
Table 4: Intraday precision data of kanamycin sulfate standard from FTIR method

\begin{tabular}{llll}
\hline No. & AUC of the day- & \\
\cline { 2 - 4 } & $\mathbf{1}$ & $\mathbf{2}$ & $\mathbf{3}$ \\
\hline 1 & 1.36783 & 1.36583 & 1.38528 \\
2 & 1.36009 & 1.37838 & 1.36475 \\
3 & 1.36353 & 1.37993 & 1.37420 \\
4 & 1.39379 & 1.37315 & 1.35890 \\
5 & 1.38797 & 1.35997 & 1.38691 \\
6 & 1.39384 & 1.37376 & 1.36047 \\
Average of AUC & 1.37784 & 0.0094 & 0.0104 \\
RDD (\%) & 0.0157 & $0.69 \%$ & $0.76 \%$ \\
\hline
\end{tabular}

Inter-day precision was done to determine the precision produced when testing variations were carried out. Variations resulted were precision measurements on three different days of analysis.
Variance coefficient value obtained from three days of testing was $0.33 \%$. This value as shown in table 5 was $\leq 2 \%$ so that it met the precision acceptance requirements.

Table 5: Interday Precision Data of Kanamycin sulfate standard using FTIR method

\begin{tabular}{ll}
\hline Day- & AUC derivate \\
\hline 1 & 1.37784 \\
2 & 1.37376 \\
3 & 1.36889 \\
Average AUC & 1.37350 \\
SD & 0.0045 \\
RSD (\%) & $0.33 \%$ \\
\hline
\end{tabular}

LOD is the smallest concentration of analyte that still provides a significant response compared to the blank. Meanwhile, the LOQ is the lowest content of sample, which has been met the criteria of accuracy and precision. The limit of detection and quantification can be derived from the calibration curve through the following mathematical equations [24]:

$$
\begin{aligned}
& S_{y / x}=\sqrt{\frac{\sum y_{i}-x^{2} y^{2}}{n-2}}=0.0127 \\
& \text { LOD }=\frac{3 s_{\text {whe }}}{b}=0,04 \% \mathrm{w} / \mathrm{w} \\
& \mathrm{LOQ}=\frac{10 \mathrm{~s}_{\mathrm{p}} \mathrm{c}}{\mathrm{b}}=0,12 \% \mathrm{w} / \mathrm{W}
\end{aligned}
$$

From the calculation result, it shown that FTIR can detect the compound until the lowest concentration or LOD of $0.04 \% \mathrm{w} / \mathrm{w}$. Then, it met the criteria of accuracy and precision at a concentration of $0.12 \% \mathrm{w} / \mathrm{w}$.

Afterwards, the range of analysis can be stated from the LOQ until the highest concentration, which is able to measured and linear to the response. So, the range is $0.12 \% \mathrm{w} / \mathrm{w}-1.5 \% \mathrm{w} / \mathrm{w}$.

The validated FTIR method was then used to determine the levels of kanamycin sulfate in the dosage form. The sample was reconstituted injection preparations from the market with a dose of $1 \mathrm{~g}$. The six vials of the sample were weighed and calculated for their averages after these were homogenized, sampled, and mixed with $\mathrm{KBr}$ with a

\begin{tabular}{|c|c|c|c|c|}
\hline Weight average of injection & $\operatorname{AUC}(n=3)$ & Average of AUC & Level (mg) & Level (\% w/w) \\
\hline $1.4237 \mathrm{mg}$ & $\begin{array}{l}1.060307 \\
1.060905 \\
1.048506\end{array}$ & $1.05657 \pm 0.00699$ & 0.99789 & $99.79 \%$ \\
\hline
\end{tabular}
concentration of $1 \% \mathrm{w} / \mathrm{w}$.

Table 6: Determination of kanamycin sulfate levels in injection preparations using FTIR

The levels of kanamycin sulfate in the injection dosage obtained as shown in table 6 were $99.79 \%$. This value shows that the samples tested to meet the requirements of the levels in Indonesian Pharmacopoeia, which are not less than $90.0 \%$ and no more than $115.0 \%$ of the amount stated in etiquette [6]. The results were compared with the determination of the level by colorimetry.

Quantitative analysis of visible spectrophotometry method is based on the absorption of light at specific wavelengths by compounds that have chromophore groups. Kanamycin sulfate does not have the group in its structure, so it needs to be derivatized first. The compound used for derivatization is ninhydrin. Ninhydrin will react with amine groups contained in various compounds, in this method ninhydrin will react with a primary amine in kanamycin to form a bright purple complex (Ruhemann's purple) after being heated at a temperature of $80-100^{\circ} \mathrm{C}$ for $5 \mathrm{~min}$, as shown in fig. 6 [13]. The resulting color gives an absorbance value at the wavelength of visible light.

Level of kanamycin sulfate was determined using the wavelength in the range 400-800 $\mathrm{nm}$. The measurement results as shown in fig. 7 shows maximum absorbance at a wavelength of $564 \mathrm{~nm}$.

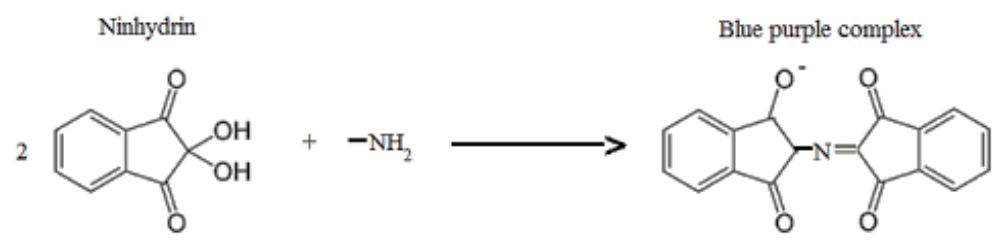

Fig. 6: The reaction of the formation of a ninhydrin complex with the primary amine (14) 


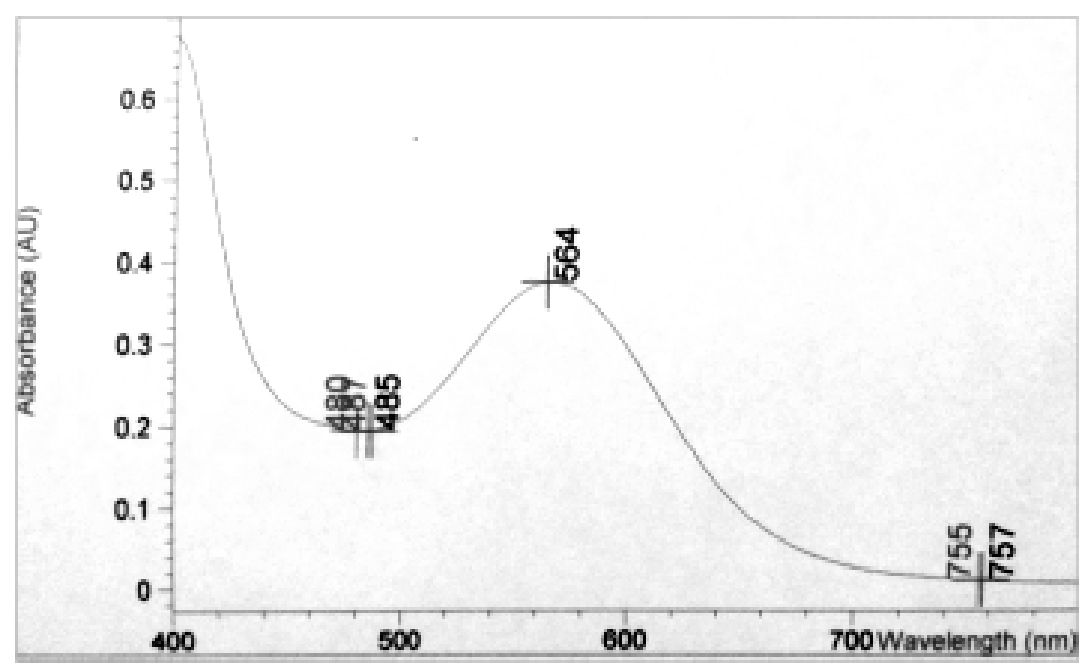

Fig. 7: Spectrum of absorbance of kanamycin sulfate derivatives

Visible spectrophotometry or colorimetry was verified by measuring the absorbance of kanamycin sulfate derivatives at six different concentrations ranging from $2-3.25 \mathrm{mg} / \mathrm{ml}$. Measurements performed at a maximum wavelength of $564 \mathrm{~nm}$, and each concentration was measured three times. The measurement results are then plotted between concentration and absorbance as shown in table 7.

Table 7: Kanamycin sulfate calibration curve data from colorimetry

\begin{tabular}{ll}
\hline Concentration $(\mathbf{m g} / \mathbf{m l})$ & Absorbance \pm SD \\
\hline 2.00 & $0.28330 \pm 0.00049$ \\
2.25 & $0.31942 \pm 0.00044$ \\
2.50 & $0.36314 \pm 0.00004$ \\
2.75 & $0.40534 \pm 0.00126$ \\
3.00 & $0.43600 \pm 0.00058$ \\
3.25 & $0.47904 \pm 0.00113$ \\
\hline
\end{tabular}

Note: $\mathrm{n}=3$, A calibration curve is generated from the data in table 7 as depicted in fig. 8 .

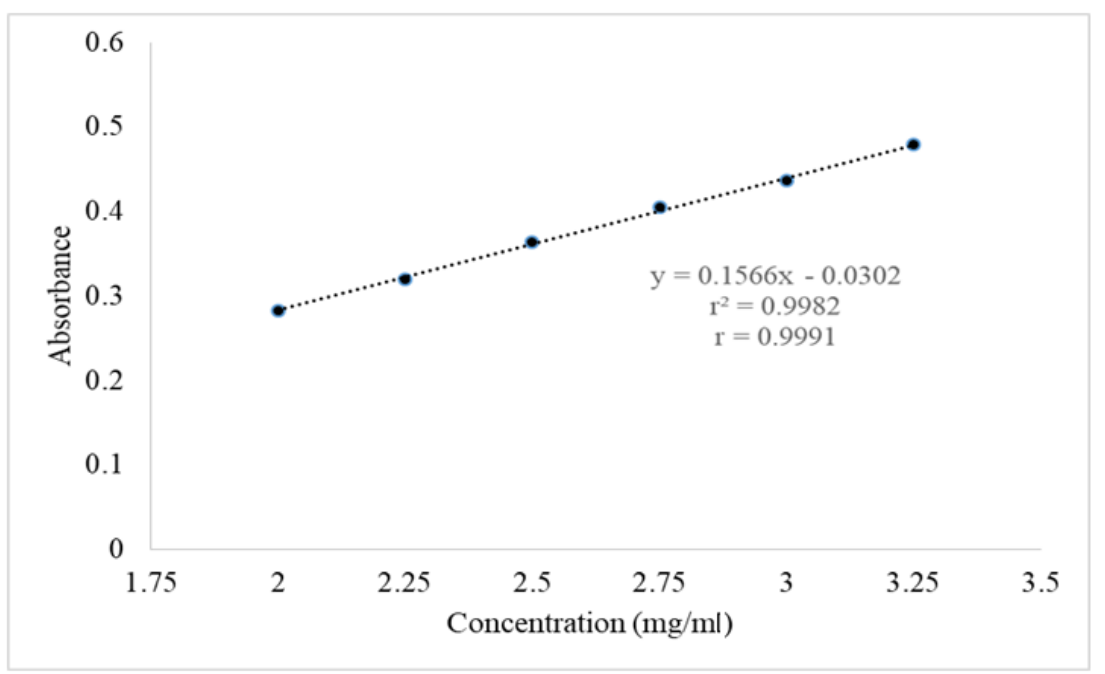

Fig. 8: Standard calibration curve of kanamycin sulfate by visible spectrophotometry method

From the curve above, we obtain a linear regression equation $\mathrm{y}=$ $0.1566 \mathrm{x}-0.0302$ in the concentration range $2-3.25 \mathrm{mg} / \mathrm{ml}$ with a correlation coefficient $(r)=0.9991$ and $V x 0=0.0084$. The values of $r$ $\geq 0.999$ and $\mathrm{Vx} 0 \leq 2.0 \%$ indicate that this method satisfied the terms of acceptance of linearity. The concentration range in the linearity test shows good results so that it can conclude that the range used in this method is $2-3.25 \mathrm{mg} / \mathrm{ml}$.
Accuracy test was done to determine the degree of closeness between the test results with actual value. Tests carried on by measuring the standard absorbance of kanamycin sulfate with concentrations equal to 80,100 , and $120 \%$ each carried out three times. Percentage of recovery obtained as shown in table 8 was $99.15 \%$; $100.51 \%$; then $101.2 \%$. These three values were in the range of $98 \%-102 \%$ so that they met the acceptability of accuracy. 
Table 8: Accuracy test data of kanamycin sulfate by visible spectrophotometry method

\begin{tabular}{llll}
\hline Concentration & Absorbance & Average of absorbance \pm SD & Theoretical absorbance \\
\hline $80 \%$ & 0.31959 & $0.31942 \pm 0.00044$ & 0.32215 \\
& 0.31974 & & \\
& 0.31892 & $0.36314 \pm 0.00005$ & 0.36130 \\
$100 \%$ & 0.36309 & & $100.51 \%$ \\
& 0.36318 & $0.40534 \pm 0.00125$ & 0.40045 \\
$120 \%$ & 0.36316 & & $101.22 \%$ \\
& 0.40677 & & \\
\hline
\end{tabular}

Note: $n=3$

Intraday precision was conducted to determine precision on the same test day or in a close time. Variance coefficient values obtained from each testing day as shown in table 9 were $0.37 \%$; $0.40 \%$; next $0.51 \%$. The three values were $\leq 2 \%$ so that they meet the precisi on acceptance requirements.
Interday precision was done to determine the precision produced when testing variations are carried out. The variations were from three different days of analysis. Variance coefficient value obtained as shown in table 10 was $0.63 \%$ because it is $2 \%$. It met the precision acceptance requirements.

Table 9: Intraday precision data of kanamycin sulfate standard using colorimetry

\begin{tabular}{|c|c|c|c|}
\hline \multirow[t]{2}{*}{ No. } & \multicolumn{3}{|c|}{ Absorbance day- } \\
\hline & 1 & 2 & 3 \\
\hline 1 & 0.36309 & 0.36107 & 0.36669 \\
\hline 2 & 0.36318 & 0.35845 & 0.36793 \\
\hline 3 & 0.36441 & 0.35935 & 0.36607 \\
\hline 4 & 0.36185 & 0.36181 & 0.36552 \\
\hline 5 & 0.36053 & 0.36250 & 0.36394 \\
\hline 6 & 0.36316 & 0.36273 & 0.36285 \\
\hline Average of absorbance & 0.36270 & 0.36098 & 0.36550 \\
\hline SD & 0.0013 & 0.0015 & 0.0018 \\
\hline RSD (\%) & $0.37 \%$ & $0.40 \%$ & $0.51 \%$ \\
\hline
\end{tabular}

Note: $n=6$

Table 10: Interday precision test data of kanamycin sulfate using colorimetry

\begin{tabular}{ll}
\hline Day & Absorbance \\
\hline 1 & 0.36270 \\
2 & 0.36098 \\
3 & 0.36550 \\
Average of absorbance & 0.36306 \\
SD & 0.0023 \\
RSD (\%) & $0.63 \%$ \\
\hline
\end{tabular}

Note: $n=3$

The calculation results showed that the colorimetry as an un-direct UV-Vis spectrophotometer method could detect samples with the lowest concentration of $0.066 \mathrm{mg} / \mathrm{ml}$. Then, it met the criteria of accuracy and precision at a concentration of $0.221 \mathrm{mg} / \mathrm{ml}$.

The colorimetry then was used to determine the levels of kanamycin sulfate in injection preparations from the market with a dose of $1 \mathrm{~g}$. Samples of six vials were balanced for each weight and calculated for their averages. After that, it was sampled, derivatized and then measured the absorbance at a maximum wavelength of $564 \mathrm{~nm}$ with a concentration of $2.5 \mathrm{mg} / \mathrm{ml}$. The kanamycin sulfate level obtained as shown in table 11 was $101.58 \%$ so that it can state that the tested sample met the requirements of the levels. Indonesian Pharmacopoeia states that the preparation should not less than $90.0 \%$ and no more than $115.0 \%$ of the amount stated in etiquette [6].

Table 11: Data on determination of kanamycin sulfate in injection preparation by colorimetry

\begin{tabular}{llll}
\hline Average of weight (mg) & Absorbance & Average of absorbance \pm SD & Level (mg) \\
\hline 1.4237 & 0.25075 & $0.24912 \pm 0.00168$ & 1.0158 \\
& 0.24740 & & $101.58 \%$ \\
& 0.24921 & & \\
\hline
\end{tabular}

The comparison parameters in table 12 are sensitivity, time of testing, which starts from weighing to measuring samples, estimating costs, and the simplicity of the method. 
Table 12: Data comparison of FTIR methods with colorimetry

\begin{tabular}{|c|c|c|c|}
\hline \multirow[t]{2}{*}{ Parameter } & \multicolumn{2}{|l|}{ Method } & \multirow[t]{2}{*}{ Interpretation } \\
\hline & FTIR & Colorimetry & \\
\hline $\begin{array}{l}\text { Linearity (correlation } \\
\text { coefficient) }\end{array}$ & 0.99975 & 0.9991 & FTIR is more linear \\
\hline Accuracy (\% recovery) & $99.18 \%-100.27 \%$ & $99.15 \%-100.51 \%$ & $\begin{array}{l}\text { FTIR is more } \\
\text { accurate }\end{array}$ \\
\hline $\begin{array}{l}\text { Intraday precision } \\
\text { (SBR) }\end{array}$ & $1.14 \% ; 0.69 \% ; 0.76 \%$ & $\begin{array}{l}0.37 \% ; 0.40 \% \\
0.51 \%\end{array}$ & $\begin{array}{l}\text { Colorimetry is } \\
\text { preciser }\end{array}$ \\
\hline $\begin{array}{l}\text { Interday precision } \\
\text { (SBR) }\end{array}$ & $0.33 \%$ & $0.63 \%$ & FTIR is preciser \\
\hline $\begin{array}{l}\text { Limit of detection } \\
(\mathrm{ppm})\end{array}$ & 400 & 660 & $\begin{array}{l}\text { FTIR is more } \\
\text { sensitive }\end{array}$ \\
\hline $\begin{array}{l}\text { Limit of quantitation } \\
(\mathrm{ppm})\end{array}$ & 1200 & 2210 & $\begin{array}{l}\text { FTIR is more } \\
\text { sensitive }\end{array}$ \\
\hline Time & $10 \mathrm{~min}$ & $30 \mathrm{~min}$ & FTIR is faster \\
\hline Cost estimation & $\begin{array}{l}\mathrm{KBr} 2 \mathrm{~g}=\mathrm{Rp} 45,000,00[25] \\
\text { Acetone (as presser cleaner): } 50 \mathrm{ml}=\mathrm{Rp} \\
10,000,00[26] \\
\text { Total }=\operatorname{Rp} 55,000,00\end{array}$ & $\begin{array}{l}\text { Aquadest: } 500 \mathrm{ml}=\operatorname{Rp} 5.000,00 \\
\text { Ninhydrine } 0.5 \mathrm{~g}=\operatorname{Rp} 99,000,00[27] \\
\text { Acetone } 20 \mathrm{ml}=\operatorname{Rp} 4,000,00[26] \\
\text { Total = Rp } 108,000,00\end{array}$ & FTIR is less costly \\
\hline Simplicity & $\begin{array}{l}\text { Easier and simpler since the sample was only } \\
\text { dispersed and compacted in its solid form } \\
\text { directly. }\end{array}$ & $\begin{array}{l}\text { Needs reaction step involved heating and } \\
\text { dissolving }\end{array}$ & FTIR is simpler \\
\hline
\end{tabular}

The table shows that the FTIR method gives better linearity, accuracy, and precision results compared to the colorimetry in the concentration range used. Also, it has advantages in terms of sensitivity, testing time, cost estimation, and simplicity of analysis compared to the opponent method. For the precision inter-day, colorimetry is higher, due to its selectivity of ninhydrin reaction which is not influenced by another component. However, FTIR has higher intra-day precision. This phenomenon indicates the directsolid measurement is suitable for assay besides for qualitative purpose. In the past, this instrument is commonly for identification, only [18]. Time by time in the last decade, FTIR developed for assay. Attenuated Total Reflectance-Fourier Transform Infrared (ATRFTIR) combined with chemometrics for mapping and to predict the level of some compounds in the complicated matrix [29]. The levels of kanamycin sulfate in injection preparations obtained by the FTIR method compared with the levels obtained by the counterpart, using unpaired data t-test. The null hypothesis fixed; namely, there was no significant difference in the level-determination result from both methods. The null hypothesis accepted if the value of the t-student count is smaller than the value of $t$ table [30]. The calculated $t$ value is determined by the mathematical equation as follows:

$$
\begin{aligned}
& \mathrm{S}_{\mathrm{p}}{ }^{2}=\frac{\left(\mathrm{n}_{1}-1\right) s_{1}^{2}+\left(\mathrm{n}_{2}-1\right) s_{2}^{2}}{\mathrm{n}_{1}+\mathrm{n}_{2}-2}=0.621325 \\
& S_{D}=\sqrt{\frac{S_{p}^{2}}{n_{1}}+\frac{s_{p}^{2}}{n_{2}}}=0.6436 \\
& \mathrm{Xr}-\mathrm{Xis}-\mathrm{LC} \\
& \mathrm{t} \text { calculation }=\mathrm{S}_{\mathrm{D}}=2.7657(\mathrm{t} \text { table }=2.77645)
\end{aligned}
$$

Based on the t-student value, here proven that both methods obtained similar content determination yields [31]. As known, many compounds which have no chromophore then must be reacted with ninhydrin for UV-analysis, such as some antibiotics, namely cefepime, cefazolin sodium and cephalothin sodium [32]. Based on this experiment, it can be suggested to be measured by FTIR on the similar wavenumber.

\section{CONCLUSION}

The developed FTIR method for determining the levels of kanamycin sulfate has met the validation criteria which include specificity, linearity, accuracy, precision, range, detection limit, and quantification limits. Kanamycin sulfate has a specific spectrum at wave numbers $1540-1480 \mathrm{~cm}^{-1}$ and provides a linear correlation within the range of $0.25-1.5 \%$. LOD and LOQ is $0.04 \%$ and $0.12 \% \mathrm{w} / \mathrm{w}$, respectively. The method also has been checked to be applied for measuring the content of the antibiotic in its reconstitution-injection dosage form succesfully.

There were no significant differences between the FTIR and colorimetry method, statistically. Both methods proof suitability as the alternative procedures in determining levels of kanamycin sulfate in injection preparations. However, FTIR method possesses double times of sensitivity, one-third time needed, a half cost, and a more straightforward due to not needing any solvents and extraction steps.

\section{AUTHORS CONTRIBUTIONS}

All the author have contributed equally

\section{CONFLICT OF INTERESTS}

Declared none

\section{REFERENCES}

1. McEvoy GK, Snow E. AHFS drug information handbook. Maryland, United States: American Society of Health-System Pharmacists; 2011.

2. Alldredge BK, Corell RL, Ernst ME. Koda-Kimble and young's applied therapeutics: the clinical use of drugs. $10^{\text {th }}$ ed. Philadelphia, USA: Lippincott Williams and Wilkins; 2013.

3. Sweetman SC. Martindale the complete drug reference. $36^{\text {th }}$ ed. London, UK: Pharmaceutical Press; 2009.

4. Brunton LL, Lazo JS, Parker KL. Goodman and gilman are the pharmacological basis of therapeutics. $11^{\text {th }}$ ed. New York, United States: McGraw-Hill; 2006.

5. Indonesian Pharmacist Institution. Informasi Spesialite Obat Indonesia. Vol. 50 $0^{\text {th }}$. Jakarta: Indonesian Pharmacist Institution; 2016.

6. Ministry of Health of the Republic of Indonesia. Pharmacopoeia Indonesia. $5^{\text {th }}$ ed. Jakarta: Ministry of Health of the Republic of Indonesia; 2014.

7. The British Pharmacopoeia Commission. British Pharmacopeia. London: British Pharmacopoeia Commission; 2013.

8. United States Pharmacopoeia Conv. USP 37/NF 32. Washington DC: US Pharmacopeia; 2014.

9. Ministry of Health of the Republic of Indonesia. Pharmacopoeia Indonesia, $4^{\text {th }}$ ed. Jakarta: Ministry of Health of the Republic of Indonesia; 1995.

10. Ahuja S, Dong MW. Handbook of pharmaceutical analysis by HPLC. New York, United States: Elsevier Inc; 2005.

11. Coates J. Interpretation of infrared spectra, a practical approach. In: RA Meyers. (Ed.) Encyclopedia of Analytical Chemistry. Canada: John Wiley and Sons Ltd; 2014. 
12. Griffiths PR. Chemical infrared fourier transform 43. Toronto: John Willey and SMS; 1975.

13. Shehzadi N, Hussain K, Khan MT. Development of a validated colorimetric assay method for estimation of amikacin sulfate in bulk and injectable dosage form. J Chem Soc Pak 2016;38:63-9.

14. Das V, Kheeci S, Inda SS. Analytical method development and its validation for estimation of kanamycin sulfate by UV-Visible spectrophotometry as bulk and in the dosage form. Int J Pharm Res Bio Sci 2017;6:19-26.

15. Nugrahani I, Dillen N. rapid assay development of diclofenac sodium coated tablet assay using ftir compared to HPLC method. Int J Appl Pharm 2018;10:43-50.

16. Chan CC, Herman L, Lee YCX. Analytical method validation and instrument performance verification. Canada: John Wiley and Sons Inc; 2014

17. Dean JA. Lange's Handbook of Chemistry. $15^{\text {th }}$ ed. USA: McGraw-Hill, Inc; 1999.

18. Furniss BS, Hannaford AJ, Smith PW. Vogel's textbook of practical organic chemistry. $5^{\text {th }}$ ed. New York, United States: John Wiley and Sons; 1989.

19. Silverstein RM, Webster FX, Kiemle DJ. Spectrometric identification of organic compounds. USA: John Wiley and Sons, Inc; 2005.

20. Harvey D. Modern analytical chemistry. New York: McGrawHill; 2000 .

21. Settle F. Handbook of instrumental techniques for analytical chemistry. New Jersey: Prentice-Hall; 1997.

22. Skoog DA. Principles of instrumental analysis. $6^{\text {th }}$ ed. USA: Thomson Higher Education; 2007.

23. Bhattacharjee, Mrinal K. Chemistry of antibiotics and related drugs. switzerland: Springer International Publishing; 2016.

24. Carlson J, Wysoczanski A, Voigtman E. Limits of quantitationyet another suggestion. Spectrochimica Acta Part B: Atomic Spectroscopy 2014;96:69-73.
25. Alfa Aesar by Thermo Fisher Scientific, 39794 Potassium bromide, FTIR Grade. Available from: https://www.alfa.com/ en/catalog/039794/. [Last accessed on 02 Oct 2017]

26. Sigma-Aldrich. Acetone Laboratory Reagent. Available from: https://www.sigmaaldrich.com/chemistry/solvents/produ cts.html?TablePage $=17292082$. [Last accessed on 02 Oct 2017].

27. Sigma-Aldrich. Ninhydrin ACS Reagent. Available from: https://www.sigmaaldrich.com/catalog/product/sial/151173 ?lang=enandregion=ID). [Last accessed on 02 Oct 2017]

28. Manyasree D, Kiran MP, Ravikumar R. CuO nanoparticles: synthesis, characterization and their bactericidal efficacy. Int Appl Pharm 2017;9:71-4.

29. Arslan FN, Caglar F. Attenuated total reflectance-fourier transform infrared (ATR-FTIR) spectroscopy combined with chemometrics for rapid determination of cold-pressed wheat germ oil adulteration. Food Anal Meth 2018;12:35570 .

30. Ethiraj R, Thiruvengadam E, Sampath VS, Vahid A, Raj J Development and validation of stability indicating spectroscopic method for content analysis of ceftriaxone sodium in pharmaceuticals. Int School Res Notices 2014 http://dx.doi.org/10.1155/2014/278173

31. Weisstein EW. Student's t-Distribution. From MathWorld-a wolfram web resource. http://mathworld.wolfram.com/Studentst-Distribution.html. [Last accessed on 17 Apr 2019]

32. Papanna RK, Krishnegowda JB, Nagaraja P. Spectrophotometric method for the determination of cefepime, cefazolin sodium and cefalothin sodium in pure and pharmaceutical dosage forms by using ninhydrin. Int Pharm Pharm Sci 2015;7:194-9. 